\title{
> A improrrogável crítica da identidade nacional no Brasil
}

$>$ The unpostponable criticism of national identity in Brazil

por Kathrin Holzermayr Lerrer Rosenfield

Graduada em Letras pela Université de Paris III (Sorbonne-Nouvelle), Mestra em Antropologia Histórica pela École des Hautes Études en Sciences Sociales e Doutora em Ciência da Literatura pela Universidade de Salzburg. Atualmente é professora titular da UFRGS, com atuação no PPGFilosofia e Editora Sênior da Revista PHILIA. Tem experiência na área de Teoria Literária, Estética, Filosofia e Literatura, Arte e Psicanálise. E-mail: kathrinrosen@gmail.com. ORCID: 0000-0002-0061-3208.

\section{por Ana Laura Boeno Malmaceda}

Mestra em Estudos Brasileiros pela Universidade de Lisboa. Doutoranda em Literatura Lusófona e Francófona no programa de Romance Languages and Literatures em Harvard. E-mail: boenomalmaceda@g.harvard.edu. ORCID: 0000-0001-9168-7255.

\section{por Guilherme Mautone}

Bacharel, Mestre e Doutor em Filosofia pela Universidade Federal do Rio Grande do Sul (UFRGS), com pesquisa em filosofia da arte e estética e ênfase em arte contemporânea. É Editor de Filosofia da Revista PHILIA, membro do Colegiado Setorial de Artes Visuais da Secretaria da Cultura do Estado do RS e docente convidado na Casa de Cultura Mário Quintana e na Casamundi Cultura. E-mail: guimautone@gmail.com. ORCID: 0000-0001-8623-6230.

O dossiê temático Culturas Brasileiras Contemporâneas surgiu com o objetivo de coligir uma diversidade de textos que problematizassem - ou, ao menos, tensionassem - certas orientações unilaterais que parecem ter lastreado as concepções de identidade, cultura, artes e educação no Brasil que se depreendem da produção científica, humanística e artística no país ontem e hoje.

Foi justamente considerando a importância dessas problematizações e tensionamentos que o dossiê procurou, portanto, somar-se às muitas ideias e vozes insurgentes que há anos têm tentado - às vezes motivadas pela esperança na utopia, outras vezes pela coragem da resistência - romper com os perigos que sempre parecem espreitar as homogeneidades culturais, as identidades fixas e as orientações unilaterais para uma caracterização positiva da nacionalidade. 
Poder-se-ia sugerir que tais impulsos redutores parecem se originar, genealogicamente, dos processos de solidificação tardia do nosso país durante seu período de formação dos estados nacionais após a Independência. Esse processo, sabemos bem, viu na própria criação ideológica, identitária e cultural, ao longo do século XIX, uma oportunidade singular para a preservação de um território de proporções continentais e intrinsecamente determinado pelas mais ricas diversidades. As anotações de D. Pedro II nas margens de seu exemplar da primeira edição de $A$ Confederação dos Tamoios, de Gonçalves de Magalhães, indicam duas ideias vagas que, no decorrer do período monárquico até seu encerramento em 1889, ganharam peso, sustentação política, institucional e econômica e um lugar cativo no imaginário dos brasileiros: "organizar moralmente a nacionalidade, formar uma elite"1. Em seguida, ao longo do século $\mathrm{XX}$, vemos novos laços nessa organização moral da nacionalidade agora capazes de atar, então, densos nós na ideia de homogeneidade étnica: leia-se, europeia e branca.

Trazer continuamente à tona as invectivas críticas que procuram denunciar essas orientações é uma tarefa que, já há alguns anos, mostra-se necessária. No entanto, diante do incontornável reconhecimento das invisibilizações, apagamentos, distorções e violências que essas orientações imprimiram sobre a nossa diversidade intelectual e cultural (especialmente sobre os legados indígena e negro), sua revisitação crítica se tornou urgente e improrrogável. É, portanto, sobre o terreno movediço das narrativas jactanciosas e convenientemente escolhidas para forjar uma identidade nacional que se deverá trilhar o caminho da busca por tudo aquilo que foi negado e recalcado da história oficial. Entre os escombros e sedimentos deste passado tantas vezes contado e recontado é que se poderá encontrar o brilho de outras versões e existências; e nelas é que deveremos depositar parte da esperança crítica de uma tradição repleta de descaminhos, engodos e armadilhas.

Não é mais possível, e tampouco aceitável, negar que tais engodos tenham existido e que hoje em dia, por meio de reaparecimentos contemporâneos, sigam

${ }^{1}$ Vide Lilia M. Schwarcz \& Heloisa M. Starling, Brasil: uma biografia, 2018, p. 283. 
imprimindo suas marcas sobre diferentes subjetividades ou sigam estereotipando as relações intersubjetivas em território nacional. Essas marcas e estereótipos, quando soltos e à revelia de qualquer lastreamento ético ou solidez institucional, culminam na perversidade da violência que nega ao outro humanidade, pensamento, expressão e, por fim, saca-lhe direitos inalienáveis. Fenômenos que parecem grassar no Brasil de 2021.

Como, portanto, essas múltiplas e caleidoscópicas heranças continuam a se incorporar na vida cotidiana de nossas instituições educativas, sociais e políticas no Brasil? Ou, diferentemente, como irão emergir retrabalhadas pelo intelecto e pela criatividade dos artistas? Como forjaram pouco a pouco seus próprios instrumentos jurídicos, seus critérios de seleção e, consequentemente, de discriminação? E como, quando não pensados ou mediados pelas consciências, impulsionam ou - tão pior... - aprisionam o âmbito das artes, da literatura, do cinema, do direito e do pensamento filosófico?

Sustentar essas interrogações de modos diferentes e por meio de diferentes disciplinas significará, especialmente hoje, reconhecer também que elas poderão, com alguma sorte, servir ao futuro, determinando outros tantos impactos sobre a formação de intelectuais, artistas e críticos sempre que se encorajarem para trilhar, nessa terra enganosa da historiografia e ideologia nacionais, suas próprias investigações sobre a história, a sociedade, a cultura e a política brasileira.

Os diferentes textos que compõem este dossiê temático se voltam, cada um à sua maneira, aos fenômenos culturais e sociais do Brasil, sobretudo às implicações materiais que os projetos de busca por uma identidade nacional geraram em nosso país. Esperamos que os textos e imagens aqui coligidos consigam, ao menos, participar de um novo projeto coletivo por meio do qual seguiremos, juntos, sustentando a importância de interrogar as identidades forjadas pela história e, sobretudo, a legitimidade de nos inquietarmos cada vez mais diante das contradições que se engendraram em nosso país.

O dossiê temático conta com um conjunto variado de artigos, ensaios livres, traduções, ensaios visuais, entrevista e resenha. Todos, sem exceção, 
inquietam-se a partir de diferentes áreas de conhecimento com as ideias de Brasil, suas origens históricas e as contradições que geram com o presente. Nós, no papel de organizadores dessa admirável coleção, só temos a agradecer a todas e todos que gentilmente aceitaram contribuir com palavras, argumentos, pesquisas, imagens e interrogações sobre o país. Fica aqui, portanto, registrado o nosso agradecimento caloroso aos autores, autoras, amigos e amigas que aceitaram compartilhar conosco suas inquietações brasileiras.

Em Capacitismo e eugenia na educação brasileira: uma reflexão a partir de aproximações epistemológicas, André Luís de Souza Lima sugere que a investigação sobre as próprias bases epistemológicas da educação pode nos dizer algo sobre a questão da exclusão de sujeitos de dentro da escola. Assim, não só a luta anticapacitista e de resistência política dentro da educação poderá denunciar os modos como as práticas educativas se consolidaram em solo nacional, mas também uma certa genealogia epistemológica sobre seus fundamentos. A chegada ao Brasil das escalas de Binet e dos planos de Galton, com suas separações intrínsecas entre supostas categorias como normais/educáveis e anormais/ineducáveis, serviria, portanto, de sustentação epistemológica para o famoso modelo biométido da deficiência e sua atual viragem na discussão de corpos padrões. Em seu lugar, Lima sugere que se adote um modelo social e contextual da deficiência, entendendo-a, sobretudo, como a construção ideológica calcada em meras distinções físicas ou psíquicas. Um relato de sua experiência docente com alunos indígenas, para os quais não há 'deficiência' e nem 'entraves' à educação e inclusão, evidencia a presença dos traços capacitistas e eugenistas nas práticas sociais educativas.

Já em O reendereçamento de obras literárias por meio do projeto gráfico: Fita Verde no Cabelo, de Guimarães Rosa, Gabriela Narumi Inoue e Paula Luersen analisam a reedição para o público infantojuvenil de 1992 do conto de Guimarães Rosa, Fita verde no cabelo, ilustrada por Roger Mello, e procuram indicar que a presença das imagens na reedição estabelece com o texto de Rosa um sentido complementar ao nível semiótico. A complementação entre as dimensões imagéticas e textuais estabelecem, portanto, uma relação de intertextualidade gerativa, onde novas relações são descortinadas aos leitores e 
imagem e texto participam juntos do processo de interpretação e de consolidação de sentidos para o trabalho artístico rosiano.

$\mathrm{O}$ artigo $\mathrm{O}$ crânio-celebridade: Antônio Conselheiro e o fracasso da degeneração racial de Isabela Fraga realiza uma investigação de diferentes documentos que noticiam ou registram especulações sobre a notória cabeça de Antônio Conselheiro após sua morte na Guerra de Canudos, em 1897. Ao retomar os textos de Nina Rodrigues e Euclides da Cunha, a investigação de Fraga aponta que ambos escritores tiveram suas expectativas de encontrar nas análises craniométricas - embasadas pela pseudo-científica frenologia da época - algum vestígio de degeneração racial. Assim, seu artigo tangencia as questões do racismo científico na virada do século XX e sugere a presença de seus resquícios em âmbito ideológico no Brasil contemporâneo.

João Cezar de Castro Rocha, em Teoria Mimética e vulnerabilidade do sujeito - Ou: René Girard, Sigmund Freud e Oswald de Andrade, propõe uma comparação entre as ideias de Girard, Freud e Oswald de Andrade relacionadas ao conceito de sujeito para, então, sugerir certas aproximações. O sujeito mimético de Girard estabeleceria com o sujeito antropofágico de Oswald de Andrade uma proximidade estrutural já que para ambos o sujeito seria sempre definido por uma relação dinâmica de assimilação do outro. A hipótese de Rocha é, portanto, a de que Girard e Andrade assimilaram, cada um a seu modo, as lições freudianas do texto social de Totem e Tabu (1913).

Em Cenas da precariedade de ontem e de hoje, José Edilson Amorim parte de uma crônica de Bráulio Tavares para sugerir a ubiquidade da noção de precariedade ao longo da história recente brasileira. Seu artigo faz uma costura entre a Revolta da Vacina, no Rio de Janeiro, e as manifestações brasileiras de 2013, 2014, o processo de impedimento de mandato presidencial de Rousseff em 2015 e, por fim, a vida cotidiana de uma trabalhadora de Brasília. Em todos estes contextos, Amorim enxerga o mundo da classe trabalhadora brasileira, seu desamparo social e sua existência diante do que chama de "espetáculos midiáticos". 
Leila Lehnen, em Textual Coups and Democratic Imaginings in Contemporary Brazilian Literature, examina de que modos a literatura brasileira contemporânea tem trabalhado artisticamente as mudanças no cenário político brasileiro desde 2013. O argumento principal de Lehnen é de que a produção literária não somente aborda a questão dos levantes e insurgências políticas, sobretudo de esquerda; mas opera ao nível intelectual promovendo uma espécie singular de ampliação da democracia na medida em que passa a organizar na tessitura literária também as questões propositivas da demanda por direitos e da disputa política. Nesse sentido, de acordo com Lehnen, a literatura brasileira estaria atuando também na criação de um imaginário democrático ao mesmo tempo reivindicativo e denunciador, circunscrevendo conflitos intrinsecamente lastreados pela nossa democracia atual, tensionada entre erosão e recriação.

O artigo Os Capitães da Areia e a coragem dos Erês: notas sobre o imbricamento da arte, música e religião, de Lia dos Santos e Rosângela de Medeiros, parte dos pressupostos trabalhados por Even-Zohar (1990) sobre a interrelação entre diferentes sistemas culturais e seus processos simbólicos para explicar a intertextualidade presente em Esú, de Baco Exu do Blues, sobretudo na faixa Capitães de Areia. O romance de Jorge Amado, a mitologia dos Erês e as fotografias de Mario Cravo Neto criam, assim, um jogo intertextual com o álbum de Baco Exu do Blues, cujas configurações culturais e identidades são teoricamente exploradas a partir de Canclini e sua teoria do hibridismo e de Ferreti.

Lilia Schwarcz, em Gilberto Freyre: Adaptação, Mestiçagem, Trópicos e Privacidade em Novo Mundo Nos Trópicos, reflete criticamente sobre a obra de Freyre a partir de sua tentativa de encontrar nas noções de adaptação cultural e de mestiçagem uma suposta singularidade brasileira. A crítica de Schwarcz mostra que a obra de Freyre acaba deslocando a análise dos fenômenos sociais e econômicos para o âmbito privado justamente em função dessas escolhas. Novo Mundo Nos Trópicos, de Freyre, é estrategicamente escolhida no artigo precisamente porque Schwarcz vê nela uma síntese do pensamento freyreano, onde se condensam os pontos problemáticos de suas propostas e as grandes linhas para a sua interpretação. 


\section{Em, El momento en que una hoja se seca: Naturaleza y crisis ambiental en} Tempo em suspensão, de Lia do Rio, Lucas Mertehikian efetua um exame e uma análise das obras de Lia do Rio que se utilizam de folhas secas como principal material plástico. $\mathrm{O}$ autor promove uma relação entre a obra de do Rio e os herbários de informação botânica que remontam ao surgimento da história natural. Nesta relação, os âmbitos afetivos e temporais densificam a ideia de uma conexão imersiva com a própria natureza auxiliada pela suspensão temporal.

\section{Luise Malmaceda colabora com Bacurau: ficção weird e estética} aceleracionista de expurgo colonial, artigo no qual procura analisar o recente filme de Mendonça Filho e Dornelles como uma ficção weird, estofada artisticamente por aspectos de futuridade, conflitos sociais e a temática do interior profundo brasileiro. A mistura de gêneros no filme também é analisada no artigo, revelando heuristicamente uma interpretação que analisa os sistemas políticos de morte tematizados por Mbembe e sua noção de necropolítica sob as roupagens artísticas de um híbrido perspicazmente chamado pela autora de cangaço gore.

Em Culturas indígenas e a ideia de nação brasileira, Maria de Fátima Souza da Silveira enfoca os problemas da busca por uma "brasilidade homogênea" e por uma ideia de nacionalidade, encabeçados pelas elites brancas brasileiras, e que acabaram por elidir os povos indígenas enquanto agentes históricos modulando, portanto, de modo decisivo não só a história brasileira, mas também a própria noção de identidade.

Meg Weeks, em Meninas Desamparadas? A Pastoral da Mulher Marginalizada e o nascimento do movimento brasileiro de prostitutas, aborda o tema do surgimento do movimento de prostitutas no Brasil a partir de uma análise dos trabalhos assistencialistas da Igreja Católica. O argumento principal da autora consiste em mostrar que o movimento não foi unicamente marcado pela democratização em território brasileiro, mas sobretudo pelo discursividade pregada pela Pastoral, relacionada com o desenvolvimento da autoestima e do valor inalienável dos indivíduos. Nesse sentido, o argumento de Weeks sugere que o movimento norteia uma rejeição do estereótipo da prostituta como vítima. 


\section{Em Como a história da escravidão pode ajudar a formar uma teoria} brasileira do direito?, Paulo Henrique Rodrigues Pereira parte de constatação de que o direito brasileiro articulou-se a partir das categorias filosóficas do liberalismo europeu e que diante do escravismo brasileiro do século XIX, esse espelhamento constituiu no Brasil institucionalidades problemáticas. Diante disso, o autor defende a necessidade de reconstruir uma teoria brasileira do direito capaz de dimensionar criticamente as peculiares de sua própria estruturação, reconhecendo sobretudo o modo como foi afetado pelo contexto da escravização.

Nos Ensaios Livres, seção aberta especialmente para este dossiê, Ana Laura Malmaceda organiza com uma pequena coletânea de poemas das escritoras Alice Sant'Anna, Catarina Lins, Maria Lutterbach e Sofia Mariutti, para a qual também contribui. Sem máscaras: uma antologia dentro de casa, na quarentena é uma composição fascinante de imagem e poesia.

Em Todo cubo branco tem um quê de Casa Grande: racialização, montagem e histórias da arte brasileira, Igor Simões nos brinda com uma revisitação de sua palestra proferida na Associação Nacional de Pesquisadores em Artes Plásticas, para, a partir da noção de racialização, discutir o caráter intrinsicamente racista da história da arte desenvolvida no Brasil, ao promover apagamentos ou estereótipos sobre as pessoas negras. Simões também realiza uma retomada de montagens recentes no cenário artístico contemporâneo, indicando que elas cumprem legitimamente um papel de insubmissa e resistente reescrita da própria história da arte no país a partir da contemporaneidade. Ademais, sugere a necessidade de que o papel (altamente prestigiado) dos curadores no sistema das artes brasileiro seja confrontado com a incontornabilidade filosófica da noção contextual de lugar de fala.

Jean Wyllys, em Por um mundo comum, oferece-nos gentilmente um ensaio ao mesmo tempo convidativo e provocativo. À luz da intertextualidade, onde imagem e discurso cooperam heuristicamente, Wyllys promove uma conversa entre seus recentes desenhos e montagens e suas reflexões sobre a política. A noção de mundo comum, ou de comum, aparece em sua reflexão como 
a invenção central da política, ao retomar, por exemplo, o pensamento de Arendt e sua noção de inter homines esse [estar entre os humanos] como um trabalho de constante fundação do lugar/coisa pública. Suas pesquisas recentes sobre as fake news, mobilizadas nos últimos anos sobretudo por uma guinada radical à direita do status quo conservador e neoliberal e que atacam perversamente políticos da esquerda brasileira, procuram sugerir de que modo essa nova estratégia de construção ideológica auxiliada pela tecnologia operam, ao nível humano, uma descaracterização da própria capacidade de distinção e pensamento - algo que reserva, nesse sentido, também relações com a noção arendtiana de banalidade do mal.

Já Felipe Alfonso em Racismo Virulento na Capital do Império nos oferece uma resenha sobre o recém-lançado livro da nova Editora Chão, um texto escrito por José Pereira Rego em 1850, chamado História e descrição da febre amarela epidêmica que grassou no Rio de Janeiro em 1850. O livro, dotado de prefácio, aparelho de notas e textos críticos, estabelece, assim, um cruel paralelismo entre a epidemia brasileira no Oitocentos e a terrível situação da pandemia da covid-19 no Brasil de 2020 e 2021. O descaso público, a falta de ação política das elites em relação ao enfrentamento da doença por meio de isolamentos sociais e quarentenas e o consequente alto índice de mortalidade em 1850 retornam, 170 anos depois, por meio da pesquisa histórica e documental, mostrando-nos que a crise do passado se repete no presente.

Na seção de traduções, o dossiê temático conta com duas traduções. Em Para Marielle. Mulheres da Maré, perigo, sementes e marés, de Geri Augusto (traduzido por Ana Laura Malmaceda e Guilherme Mautone), a importante pesquisadora, intelectual e ativista política promove uma exegese generosa e perspicaz da dissertação de mestrado de Marielle Franco (postumamente publicada pela n-1 Editora), sugerindo que as descrições e análises de Franco sobre as ocupações militarizadas nas favelas do Rio de Janeiro entre 2008 e 2014 operam como motivadores para o desenvolvimento de uma verdadeira filosofia política interessada, sobretudo, pelos temas do direito à cidade, das relações entre espaços público e privado e do cerceamento da coisa pública pela radicalização das ideologias neoliberais no Brasil. A análise mais contundente de Franco, 
insiste Augusto, é a de que no Brasil a instalação plena de um Estado Neoliberal acarreta, como consequência, um Estado Penal.

Já Flora Thomson-DeVeaux nos brinda com uma brilhante tradução para o inglês de poemas de Mugido, de Marília Floôr Kosby, introduzida por Thomaz Amancio. O livro de Marília Floôr Kosby, recentemente publicado pela Editora Garupa em 2018, e finalista do Prêmio Jabuti na categoria poesia no mesmo ano, constela um conjunto de poemas que, a partir das memórias de infância da autora, pontuadas pelos contextos rurais do interior do estado do Rio Grande do Sul, coloca o animal no centro da formulação poética.

O dossiê temático Culturas Brasileiras Contemporâneas também abriu especialmente uma seção de entrevista. Nela, Ana Paula Kojima Hirano apresenta Um encontro com Ferreira Gullar, resultante de uma conversa com o artista e intelectual brasileiro pouco antes de sua morte. O diálogo é atravessado pelas artes visuais, literatura, lembranças do ativismo político e pelas reflexões filosóficas. As fotografias de Hirano não só ilustram para as leitoras e leitores o encontro, mas também compõem com seu texto, suas lembranças da conversa e com a entrevista uma atmosfera de inquietante intimidade, onde o reconhecimento da trajetória intelectual e artística de Gullar enfrenta o dinamismo da própria vida ao longo do tempo e as contradições dessa condição.

Nos Ensaios Visuais, a artista gaúcha Claudia Hamerski nos oferece $\mathbf{O}$ desenho na borda. Seu processo, inicialmente concentrado no desenho, ali desdobra novas amplitudes poéticas, abraçando uma interrogação artística que vai além da exploração expressiva ou formal da superfície. O reconhecimento da borda do suporte como um limite intransponível do pictórico, ou como o que tradicionalmente definiu a essência do disegno, leva a artista a superar o entrave formal e a precipitar-se para além de sua borda: na materialidade dos resíduos, na potência da escolha conceitual, na descoberta de um espaço vital que está para além do espaço pictórico. Assim, é à margem do desenho que outro tipo de ação artística se dinamiza em seu trabalho, levando-a a explorar objetos físicos e situações instalativas. Voltar, depois da exploração, precisamente para o ponto de início é também, nesse sentido, enfrentar-se com as próprias ideias que 
movem a arte muito antes de sua corporificação em um suporte ou outro. É, portanto, reconhecê-la como algo pensante, mental.

Já Daniela Amon, com (EN)TERRA BRASILIS, abre-nos um livro no qual dá a ver um novo Brasil. O símbolo mais pregnante para os brasileiros - e que desde 2018 é alvo de disputa política e ideológica - é paulatinamente soterrado pela tinta de terra vermelha ao folhar de cada página. A leitura desse livro não só denuncia o descalabro sanitário que assola do país desde 2020 e que enterrou já mais de 400.000 brasileiros, mas também problematiza a própria ideia de Brasil já presente de modo incipiente no famoso mapa de Lopo Homem, feito em 1519.

Em Moças Quitandeiras, Karina Nery produz pequenas disrupções insurgentes sobre rótulos de leite condensado que, pelo menos para os brasileiros, estão semanticamente marcados pelo protagonismo semiótico da famosa Moça da marca Nestlé: uma leiteira branca vestindo roupas tipicamente europeias. Nery produz sobre a notória moça - recorrendo ao expediente pósprodutivo, conforme pensou Bourriaud - uma substituição contundente capaz de fazer aparecer representações das quitandeiras, mulheres negras que no período colonial assumiram um papel de protagonismo social, econômico e afetivo nas comunidades em que comercializavam seus quitutes. Pouquíssimo lembradas pela historiografia brasileira tradicional e até mesmo pelos registros documentais e pela memória coletiva, as quitandeiras são colocadas por Nery num lugar de destaque nos novos rótulos do produto com a intenção de enaltecer o protagonismo, tantas vezes invisibilizado, dessas mulheres. Ademais, o leite condensado, ingrediente tão presente nas receitas da confeitaria brasileira, em nossos atavismos gustativos e em nossa fome de doce, problematiza a famosa cultura do doce no Brasil como estando calcada, sobretudo, no latifúndio da cana de açúcar para fins coloniais e no trabalho das pessoas negras escravizadas. Nery sugere, portanto, que o sabor doce tão amado pelos brasileiros ostenta pequenas e inquietantes notas de amargor histórico.

Omar Salomão, em Tentativa II, convida-nos para com ele embarcar em uma viagem/meditação entre imagens e discursos, depois de sermos, junto dele, confrontados com o punctum de post-its e cartões postais de sua parede. As 
diminutas notas para si mesmo e as pinceladas sinuosas de uma pintura de Van Gogh descortinam uma investigação tateante sobre o problema da não-figuração (que Salomão designa como abstração) nas artes e sobre o trabalho psíquico do sintoma: cerne da subjetividade, deiscência existencial e origem do discurso, conforme pensou Lacan. Nesse sentido, os artistas e escritores loucos seriam, na melhor tradição artística hölderliniana, aqueles capazes de capturar um pequeno brilho/acontecimento na realidade que teima em se apagar.

Em Brasil 2018-2020: um exercício fotográfico em processo, Ricardo Alves apresenta uma seleção de fotografias relativas ao seu projeto Brasil, no qual utiliza o ato fotográfico como modo de apreender, no cotidiano, algum tipo de registro sobre o próprio país.

Para além do dossiê temático, também se registram colaborações enviadas autonomamente por pesquisadoras e pesquisadores brasileiros para nossa submissão livre. Nos artigos, Denise Estácio, em From Amelioration to Redemption: Discussing Patricia Rozema's Adaptation of Mansfield Park, analisa a adaptação do livro de Jane Austen para o cinema, a partir do tema da escravização. Já Josiana Andrade, em Simone de Beauvoir e a dimensão metafísica da existência: uma análise de $\boldsymbol{A}$ convidada, parte de escritos de Beauvoir e das concepções sobre o romance metafísico de Merleau-Ponty para sugerir precisamente o que constituiria a dimensão metafísica da existência, marca essencial deste gênero, e que se encontraria no romance de Beauvoir. José Dias e Junior Cunha, em Sobreposições: Shakespeare, Bene e Deleuze em agenciamento, promovem um estudo das relações filosóficas e artísticas entre Bene, Deleuze e Shakespeare. Nos Ensaios Visuais, Guilherme Cavalcante, em Amiúdes Cambiantes, apresenta reflexões sobre a fotografia, a história e a teoria fotográfica, entremeando suas reflexões com imagens. Patricia Guibes, em Fatiamento da paisagem, explora as experiências de dissolução referencial para situação no espaço fotográfico ao recortar estrategicamente fotografias de paisagem. E Matheus de Simone, em Muragens, insere vídeos do mar de Cabo Frio durante a ressaca em um painel de LED para publicidade na cidade de Juiz de Fora, promovendo uma discussão sobre a construção e o uso do espaço público. 
Esperamos que as leitoras e os leitores deste terceiro volume da Revista PHILIA | Filosofia, Literatura \& Arte apreciem os textos coligidos no dossiê temático, bem como os submetidos espontaneamente. Desejamos a todas e todos uma boa leitura e, sobretudo, coragem, força e atenção para continuarmos nos interrogando e produzindo arte durante esse momento tão duro que atravessamos.

\section{Referência}

SCHWARCZ, Lilia; STARLING, Heloisa. Brasil: uma biografia. São Paulo: Companhia das Letras, 2018, 709 pgs.

\section{Referência para citação desta apresentação} ROSENFIELD, Kathrin; MALMACEDA, Ana Laura; MAUTONE, Guilherme. Apresentação - Por uma improrrogável crítica da identidade nacional no Brasil. Revista PHILIA | Filosofia, Literatura \& Arte, Porto Alegre, volume 3, número 1, p. xiii - xxv, maio de 2021. 